\title{
Nanopartiküler Așılar
}

\author{
Evrim DÖNMEZ ${ }^{1 *} \quad$ Hafize Tuğba YÜKSEL DOLGUN² $\quad$ Şükrü KIRKAN ${ }^{2}$ \\ ${ }^{I}$ Aydın Adnan Menderes Üniversitesi, Sağlık Bilimleri Enstitüsü, Mikrobiyoloji Anabilim Dalı, Aydın, Türkiye \\ ${ }^{2}$ Aydın Adnan Menderes Üniversitesi, Veteriner Fakültesi, Mikrobiyoloji Anabilim Dalı, Aydın, Türkiye
}

Atıf yapmak için: Dönmez, E., Dolgun Yüksel, H. \& Kırkan, Ş. (2021). Nanopartiküler Aşılar. Anadolu Çev. ve Hay. Dergisi, 6(4), 578-584. How to cite: : Dönmez, E., Dolgun Yüksel, H. \& Kırkan, Ş. (2021). Nanoparticular Vaccines. J. Anatolian Env. and Anim. Sciences, 6(4), 578-584.

*Sorumlu yazarın: Evrim DÖNMEZ

Aydın Adnan Menderes Üniversitesi, Sağlık Bilimleri Enstitüsü, Mikrobiyoloji Anabilim Dalı, Aydın, Türkiye.

$\triangle$ : donmezevrim95@gmail.com
Öz: Nanoteknoloji, 1-100 nm aralığında küçük bir ölçekte maddenin uygulamalı imalat ve manipülasyon bilimidir. Özellikle aşı biliminde nanoteknolojinin kullanımı son yıllarda hızla ortaya çıkmış ve "nanovasinoloji" nin doğmasına yol açmıştır. Nanoteknoloji, hücresel ve humoral bağışıklık tepkilerini artırma firsatı sunan nano taşıyıcı tabanlı uygulama sistemleri sayesinde aşı gelişiminde gün geçtikçe daha da önemli bir rol oynamaktadır. Nanopartikül (NP) tabanlı aşı uygulamaları, aşıları erken bozulmaya karşı koruyabilmekte, stabiliteyi arttırmakta ve iyi adjuvan özelliklerine sahiptir. Nanopartiküller, çeşitli antijenlerin belirli dokulara ve organlara verilmesi için kullanılabilen, biyolojik olarak parçalanabilen, minimum toksisiteye sahip özellikleri ile geleneksel aşı yöntemlerine karşı etkili ve alternatif platformlar sağlamaktadır. Virüs benzeri partiküller, lipozomlar, ISCOM'lar, polimerik, inorganik nanopartiküller ve emülsiyonlar gibi ölçek dışı boyuttaki materyaller, hem aşı antijenlerini stabilize edebilen hem de adjuvan olarak işlev görebilen potansiyel dağıtım araçları olarak dikkat çekmektedir. Nanopartikül materyalinin bileşimi, nanopartiküllerin taşınması ve farmakokinetik özelliklerinde, salınım hızında ve hücresel alımda, biyolojik olarak parçalanabilirliğinde ve biyouyumluluğunda önemli bir role sahiptir. Nanopartiküler aşıların, COVID-19 gibi hızla ortaya çıkan pandemilerde ve aşılama ile kontrol altına alınamayan kanserler dahil olmak üzere birçok hastalık için gelecekte aşı geliştirmeye rehberlik edebileceği düşünülmektedir. Bu derleme; nanopartiküllerin fiziksel özellikleri ve nanopartiküler aşı çeşitleri ile ilgili bilgiler sunmakta ve nanopartikül tabanlı aşı teknolojileri kullanılarak yapılan çalışmalara genel bir bakış sağlamaktadır.

Anahtar kelimeler: Aș1, COVID-19, nanopartikül, nanoteknoloji.

\section{Nanoparticular Vaccines}

\begin{abstract}
Nanotechnology is the applied science of making and manipulating matter on a small scale in the range of 1-100 $\mathrm{nm}$. The application of nanotechnology, particularly in vaccine science, has developed rapidly in recent years, leading to the birth of "nanovasinology". Nanotechnology is playing an increasingly important role in vaccine development, thanks to nanocarrier-based delivery systems that offer the possibility of enhancing cellular and humoral immune responses. Nanoparticle-based vaccine applications can protect vaccines from premature spoilage, increase stability, and have good adjuvant properties. NPs, with their biodegradable, minimally toxic properties, provide effective and alternative platforms to traditional vaccine methods that can be used to deliver various antigens to specific tissues and organs. Virus-like particles, liposomes, ISCOMs, polymeric inorganic nanoparticles, and emulsions; out-of-scale materials are attracting attention as potential delivery vehicles that can both stabilize vaccine antigens and act as adjuvants. The composition of the nanoparticle material plays an important role in the transport and pharmacokinetic properties of the nanoparticles, the rate of release and cellular uptake, biodegradability and biocompatibility. It is thought that nanoparticular vaccines may guide the development of vaccines for many diseases in the future, including rapidly emerging pandemics such as COVID -19 and cancers that cannot be controlled by vaccination. This review; It provides information on the physical properties of nanoparticles and nanoparticle vaccine types and reviews studies using nanoparticle-based vaccine technologies.
\end{abstract}

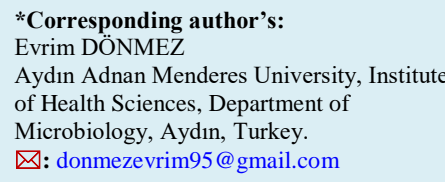




\section{GíRIŞ}

Aşılama, birçok bulaşıcı hastalığın azaltılmasında önemli bir role sahiptir. Aşılama alanındaki üretim ve gelişmeler çok iyi durumda olsa da, bazı hastalıklar için henüz etkili bir aşı bulunmamaktadır. Yeni nesil aşıların üretimi için aşıların tamamen güvenli ve verimli olması gerekmektedir (Kheirollahpour vd., 2020).

Nanoteknoloji, aşı üretimi alanındaki sorunlara karşı hücresel ve humoral bağışıklığı artırma firsatı sunan nano taşıyıcı tabanlı uygulama sistemleri sayesinde aşı gelişiminde gün geçtikçe daha da önemli bir rol oynamaktadır (Altenburg vd., 2014). Nanopartiküler bazlı uygulamalar iyi bir adjuvan görevi görmekte, aşıları erken bozulmaya karşı korumakta, stabiliteyi arttırmakta ve ayrica bir immunojenin antijen sunan hücrelere (APC) sunulmasında yardımcı olabilmektedir. Subunit aşılara göre güçlü immunojenisiteye ek olarak, nanopartikül aşılar canlı, zayıflatılmış aşılara kıyasla gelişmiş güvenlik profilleri sergileyebilmektedir. Tüm hücre aşılarının aksine, nanopartiküller hiçbir genetik/replikatif materyal içermemektedir. $\mathrm{Bu}$ durum bağışıklık sistemi zayıf olanlarda görülebilecek aşıya bağlı infeksiyon veya çapraz bağışıklık oluşumunun olasılığını sınırlamaktadır. Nanopartikül aşılar, rekombinant ekspresyon veya kimyasal sentez ile üretilen 1-1000 nm'lik bir nano ölçekte replikatif olmayan, organize yapılar için geçerli olan aşı türü olarak tanımlanmaktadır (Keller vd., 2014).

Nanopartikül (NP) tabanlı aşı geliştirme çalışmaları, inatçı patojenlere karşı maksimum koruyucu bağışıklığı özel olarak geliştirme şansı sunmaktadır (Altenburg vd., 2014). NP' ler hem kontrollü antijen salınımı hem de çoğu aşının yarılanma ömrünü uzatma yeteneklerine sahiptir ve bağışıklık güçlendirici olarak tek başlarına da hareket edebilirler (Keller vd., 2014). NP'lere karşı immun yanıtı arttırmak için aşılar polimerik NP'ler, inorganik NP'ler, lipozomlar, immunostimülatör kompleksler (ISCOM'lar), virüs benzeri partiküller (VLP'ler) ve emülsiyonlar dahil olmak üzere çeşitli maddelerden oluşmaktadır (Kheirollahpour vd., 2020).

$\mathrm{Bu}$ derlemede nanopartiküler aşı teknolojilerinin genel özellikleri, çeşitleri ve kullanım alanları bilimsel kaynaklar eşliğinde ele alınmıştır. Nanopartiküler aşılar tasarlanırken hücresel alım ve özgüllüklerini belirleyen kriterlerden bahsedilmiş, son yıllarda hızla gelişmekte olan bu teknolojinin ilerideki çalışmalara yol göstermesi amaçlanmıştır.

\section{Nanopartiküllerin Fiziksel Özellikleri:}

Kompozisyon, boyut, yük, morfoloji, hidrofobisite ve etki şekli, NP'lerin ortaya çıkardığı toksik etkileri ve immun yanıtı etkileyen önemli hususlardır. NP'lerin boyutu, hücresel alım ve özgüllüklerini belirlemektedir (Reddy vd., 2007). Küçük NP'lerin (20-200 nm) yerleşik dentridik hücreler (DH) tarafindan kolaylıkla hücre içine alındığı, daha büyük (500-2,000 nm) NP'lerin göç eden DH'ler tarafından etkili bir şekilde alındığı tespit edilmiştir (Manolova vd., 2008). 200 nm'den küçük NP'ler, lenf düğümlerine drene edilirken, $20 \mathrm{~nm}$ aralığına kadar olan partiküllerin APC'lere uygun bir şekilde taşındığı gözlemlenmiştir (Reddy vd., 2007).

Nanopartiküllerin yüzey yükü, hedef hücrelerde bulunan yüzey molekülleri ile etkileşimden sorumludur (Zhu vd., 2014). Foged vd. (2005) katyonik polisteren NP'lerin, nötr yüzey yüklü NP'lere kıyasla APC'ler tarafından verimli bir şekilde internalize olduğu ispat etmiştir. Bu durumun katyonik NP'ler ile anyonik hücre membranları arasındaki elektrostatik etkileşimlerden kaynaklandığı düşünülmektedir (Foged vd., 2005).

Nanopartiküllerin şekli, konakçı hücrelerine antijen salınım hızında kritik bir belirleyicidir (Dobrovolskaia vd., 2008).Küresel altın NP'ler, çubuk şeklindeki NP'lere kıyasla (Prego vd., 2010) etkili bir şekilde internalize olduğu ve daha güçlü immun yanıt oluşturduğu belirlenmiştir (Niikura vd., 2013). NP'lerin şekli konakçı hücre içindeki lokalizasyonuda belirlemektedir, nano çubuklar çekirdeğe aktarılırken, nano tabakaların sitoplazmada tutulduğu tespit edilmiştir (Dobrovolskaia vd., 2008).

Nanopartiküllerin hidrofobisitesi, hidrofobik parçaların tanınması, çözünür proteinler ve bağışıklık hücreleri ile etkileşimde önemli bir rol oynamaktadır (Kim vd., 2013). Moon vd. (2011) yaptıkları araştırmada hidrofobik polimerik NP'lerin, hidrofilik polimerik NP'lerden daha güçlü sitokin indükleyiciler olduğu tespit etmiştir. Hidrofobik NP'lerin proinflamatuar sitokin kodlayan genlerin ekspresyonunu düzenleyerek opsonizasyon sürecini kolaylaştırdığ vd., 2011).

Nanopartiküllerin yüzey modifikasyonu, ligand özgüllüğünü ve APC'ler ile etkileşimi değiştirmektedir ve bir molekülün immunojenikliğini artırabilmektedir (Reddy vd., 2007). Yersinia pestis F1 antijen kaplı altın NP'lerin (AuNP'ler), konjuge olmayan antijenlere kıyasla daha yüksek seviyelerde antikor ve sitokin tepkileri ürettiği gözlemlenmiştir (Gregory vd., 2012).

Nanopartiküllerin Hedef Bölgeye Iletimi ve İmmun Yanıtı Aktifleştirmesi: Kontrollü bir şekilde aş1/ilaç hazırlamak için NP'ler, bazı akut ve kronik inflamatuar hastalıklara karşı terapötik stratejiler geliştirmek amacıyla kullanılmaktadır (Chu vd., 2015). Yapılan araştırmalarda viral, bakteriyel veya fungal enfeksiyonlara karşı $\mathrm{T}$ hücre aktivitesini düzenlemek için birçok NP bazlı terapötik strateji geliştirilmiştir (Kolaczkowska ve Kubes, 2013; Perisé-Barrios vd., 2014; Temchura vd., 2014; Zhu vd., 2014). Lipozom NP ile kapsüllenmiş antijenler, antiviral siRNA, retroviral 
ilaçlarda kullanılmış ve dendrimerler, APC'ler tarafindan CD4+ $\mathrm{T}$ hücrelerine daha iyi şekilde sunulduğu belirlenmiştir. (Kolaczkowska ve Kubes, 2013; PeriséBarrios vd., 2014). NP'ler ile konjuge edilmiş ovalbumin (OVA) ve tek bir PLGA (polilaktik asit-ko-glikolik asit) NP dozu verilmesi sonucunda, MHC sinıf I-II ekspresyonu artmış ve güçlü antikor üretimi ortaya çıkmıştır (Temchura vd., 2014). NP'lerin anti-tümör veya anti-viral immun yanıtları gerçekleştirmek için spesifik olarak DH'leri aktive ettiği gösterilmiştir (Zhu vd., 2014).

\section{Alanlart}

Nanopartikül Çeşitleri ve Aşılarda Kullanım

Inorganik NP'ler: İnorganik NPler, immun yanttı arttırmak için antijenlerin hem adjuvanları hem de uygulama araçları olarak kullanılmaktadır. Altın, karbon, silika, alüminyum bazlı, kalsiyum fosfat (CaPNP'ler) ve manyetik NP'ler ana inorganik NP'lerdir (Xu vd., 2012; Yu vd., 2013; Temchura vd., 2014; Tao\&Gill, 2015). Altın NP'ler kullanılarak viral ve bakteriyel antijenlerin verilmesi sonucunda, farelerde influenza, immun yetmezlik virüsü, ayak, ağız ve tüberküloz hastalıklarına karş1 konakçıda güçlü immun yanıt oluştuğu, hsp65 antijenini kodlayan plazmid DNA'nın kapsüllenmesi ile de enfekte farelerde Mycobacterium tuberculosis'de önemli bir azalma tespit edilmiştir (Xu vd., 2012; Tao\&Gill, 2015). Silika bazlı NP'ler, aşı moleküllerinin hedef hücrelere iletimi için yüzeylerinde belirli fonksiyonel grupları tanıtmak için kullanılabilen bol miktarda silanol grupları içermektedir (Yu vd., 2013). Alumlar, tetanoz, difteri ve grip gibi antijene özgü immun yantları güçlendirmek amacıyla aşılarda en yaygın olarak kullanılan yardımcı maddelerdir (Kheirollahpour vd., 2020). CaPNP'ler mukozal bir adjuvan olarak kullanılmaktadır (Temchura vd., 2014).

Polimerik NP'ler: Polimerik NP'ler, biyouyumluluk, öngörülebilirlik, biyolojik bozunma, stabilite, kolay yüzey modifikasyonu ve güvenlikleri gibi bazı özelliklere sahip olmaları nedeniyle aşı uygulamasında büyük ilgi görmektedir (Shae vd., 2016). Polimerik NP'ler doğal polimerik ve sentetik polimerik NP'ler olarak iki ana türe ayrılmaktadır. Aljinat, hyaluronik asit (HA) ve kitosan en yaygın kullanılan doğal polimerik NP'lerdir. Kitosan kolay fabrikasyonu, toksik olmamas1, istenen şekil ve boyutlara kolayca değiştirilebilmesi nedeniyle çalışmalarda geniş çapta incelenmektedir (Kheirollahpour vd., 2020) Kitosan NP'ler HBV antijenleri (Borges vd., 2008), DNA aşısı (Zhao vd., 2012) ve Newcastle hastalığı aşısı (Feng vd., 2013) için nano taşıyıcı olarak kullanılmıştır. Kitosan NP'ler kullanarak $M$. tuberculosis lipidlerinin verilmesi sonucunda güçlü humoral ve hücresel yanıtlar oluştuğu tespit edilmiştir (Das vd., 2017).
Sentetik Polimerik NP'ler: Aşı uygulaması için en yaygın olarak kullanılan polimerik NP'ler, PLGA veya polilaktik asit (PLA)'dır. PLGA NP'ler, hidrofobik antijenler, tetanoz toksoid, hepatit-B virüs antijenleri, Bacillus anthracis dahil olmak üzere bir çok antijen türünde denenmiştir (Demento vd., 2012). PLGA, biyolojik olarak uyumlu ve mekanik olarak güçlü bir polimerdir ve Amerikan Gıda ve İlaç Dairesi (FDA) ve Avrupa Tıp Ajansı (EMA) tarafından onaylanmıştır. PLGA konjuge antijenlerin kullanımı, mikobakteri enfeksiyonuna karşı güçlü immunostimülatör özellik göstermiştir (Demento vd., 2012; Manish vd., 2013; Thomas vd., 2011).

Lipozomlar: Lipozomlar, düşük toksisiteleri ve immünojeniteleri, klinik kullanımda güvenlikleri, hazırlama kolaylığı ve ticari ölçeklerde kolay üretilebilirlikleri nedeniyle nanopartiküler aşı uygulamaları için ilgi çekici malzemelerdir (Moon vd., 2011). Moon vd. (2011) çok katmanlı lipid veziküllerde hapsolmuş antijenik proteinlerin verilmesi sonucunda, güçlü T ve B hücre yanıtı ortaya çıkardığını tespit etmiştir (Moon vd., 2011). Ribeiro vd. (2013) lipozomları kullanarak mantar enfeksiyonuna (Paracoccidioides brasiliensis) karşı güçlü koruyucu immunite oluştuğunu tespit etmişlerdir.

İmmunostimülatör Kompleksler (ISCOM'lar): İmmunostimülatör kompleksler yaklaşık $40 \mathrm{~nm}$ boyutunda kafes benzeri parçacıklardır ve saponin adjuvanı Quil A ile bir protein antijeni, kolesterol veya fosfolipitin birleştirilmesiyle üretilmektedir (Kheirollahpour vd., 2020). ISCOM bazlı aşılar, hem antikor hem de hücresel immun yanıtı geliştirmek ve hidrofobik antijenleri yakalamak için kullanılmaktadır (Alexyuk vd., 2019).

Virüs Benzeri Partiküller: Virüs Benzeri Partiküller (VLP), genetik materyali ve enfektivitesi olmayan partiküller oluşturmak için viral antijenlerin kendi kendine birleşen protein yapılarından yararlanmaktadır. VLP'ler, nükleik asitlerden oluşmayan boş yapılardır ve çoğalamamaktadırlar. VLP'ler salgınlara karşı hızla mücadele etmek için tasarlanabilmektedir. VLP aşıları, NP'lerin en önde gelen ticarileştirilmiş sınıfıdır (Kheirollahpour vd., 2020). VLP'ler zayıf antijenlerin immunojenisitesini arttırmaktadır (Gao vd., 2018). Birçok VLP tabanlı aşı lisanslanmıştır ve/veya faz çalışmaları devam etmektedir. (Tablo 1).

Emülsiyonlar: Emülsiyonlar geleneksel olarak aşı formülasyonunda yıllardır kullanılmaktadır ve son zamanlarda aşı dağıtım sistemleri olarak çalışılmaktadır. Nano ölçekli emülsiyonlar, iki karışmayan sıvı faz, emülgatör ve eksipiyandan oluşmaktadır. Bu nano boyutlu aşılar suda yağ ve yağda su emülsiyonları olarak iki geniş sınıfa ayrılır (Kheirollahpour vd., 2020). Antijen taşıyarak veya antijenlerle karıştırılarak aşı uygulamasında 
kullanılabilirler. Burun mukozasına nüfuz edebilirler ve antijeni APC'lere daha daha verimli bir şekilde taşıyabilirler (Shah vd., 2010). Bu NP'ler çoğunlukla aşı geliştirmede adjuvan olarak kullanılmaktadır. MF59TM influenza aşılarında kullanılan güvenli ve güçlü bir aşı adjuvanıdır (O'Hagan, 2007).

Dendrimerler: Aşı uygulamasında polipropilenimin (PPI) ve poliamido amin (PAMAM) en yaygın olarak kullanılan dendrimerlerdir (Chahal vd., 2016). Dendrimerle kapsüllenmiş antijenlerin; Ebola virüsü, H1N1 influenza ve Toxoplasma gondii'ye karşı güçlü antikor ve T hücre yanıtı oluşturduğu tespit edilmiştir (Chahal vd., 2016). Bahadoran vd. (2016) PMAM dendrimerinin, HIV antijenin hücresel alımını artması nedeniyle aşı etkinliğinde önemli bir artış oluşturduğunu belirlemiştir.

Günümüzde bulaşıcı hastalıklar için geniş bir nanopartikül aşı yelpazesi (sentetik platformlar dahil) oluşturulmakta ve değişik klinik fazlarda nanopartiküler aşılar üzerine çalışmalar devam etmektedir (Tablo 1).

Tablo 1. Bulaşıcı hastalıklar için ruhsatlı veya klinik geliştirme aşamasında olan nanopartiküler aşı örnekleri (U.S. National Library of Medicine-Clinical Trials, 2021).

Table 1. Examples of nanoparticular vaccines licensed or under clinical development for infectious diseases (U.S. National Library of Medicine-Clinical Trials, 2021)

\begin{tabular}{|c|c|c|c|c|}
\hline Hastalık & Materyal & Klinik fazı & Deneme numarası & Şirket \\
\hline Hepatit B & VLP & Lisanslı & Recombivax HB Engerix-B0 & Merck GSK \\
\hline HPV & VLP & Lisanslı & Gardasil & Merck GSK \\
\hline Hepatitis E & VLP & Lisansl1 & Hecolin & Innovax \\
\hline Influenza & Virosome & Lisansl1 & Inflexal & Crucell \\
\hline Hepatitis A & Virosome & Lisansl1 & Epaxal & Crucell \\
\hline Malaria & VLP & Faz 3 & NCT00866619 & GSK \\
\hline Influenza & VLP & Faz 3 & NCT03301051 & Medicago \\
\hline RSV & VLP & Faz 3 & NCT02624947 & Novavax \\
\hline Norovirus & VLP & Faz 2 & NCT03039790 & Takeda \\
\hline HSV & Liposome & Faz 2 & NCT02837575 & Vical \\
\hline Tuberculosis & Liposome & Faz 2 & NCT01755598 & GSK \\
\hline HSV & Nanoemulsion adjuvant & Faz 2 & NCT00453401 & NanoBio \\
\hline Influenza & VLP & Faz $1 / 2$ & NCT02078674 & Novavax \\
\hline HIV & Liposome & Faz $1 / 2$ & NCT03122223 & GSK \\
\hline HSV & Matrix $M$ adjuvant & Faz $1 / 2$ & NCT01667341 & Genocea \\
\hline Influenza & Matrix $\mathrm{M}$ adjuvant & Faz $1 / 2$ & NCT03293498 & Novavax \\
\hline Influenza & Self-assembling Ferritin & Faz 1 & NCT03186781 & NIAID \\
\hline Tuberculosis & Self-assembling IMX313 & Faz 1 & NCT01879163 & Imaxio \\
\hline Malaria & Self-assembling IMX313 & Faz 1 & NCT02532049 & Jenner Institute \\
\hline Dengue & Liposome & Faz 1 & NCT01502358 & Vical \\
\hline Candidiasis & Virosome & Faz 1 & NCT01057131 & Pevion \\
\hline Hepatitis C & Virosome & Faz 1 & NCT00445419 & Pevion \\
\hline Ebola & Matrix $\mathrm{M}$ adjuvant & Faz 1 & NCT02370589 & Novavax \\
\hline Malaria & Matrix $M$ adjuvant & Faz 1 & NCT01669512 & Genocea \\
\hline Influenza & Matrix $\mathrm{M}$ adjuvant & Faz 1 & NCT01444482 & Isconova $\mathrm{AB}$ \\
\hline Dengue & ISCOMATRIX adjuvant & Faz 1 & NCT01477580 & Merck \\
\hline HPV & VLP+ISCOMATRIX adjuvant & Faz 1 & NCT00851643 & Merck \\
\hline Influenza & ISCOMATRIX adjuvant & Faz 1 & NCT00851266 & Merck \\
\hline Influenza & Nanoemulsion adjuvant & Faz 1 & NCT01333462 & NanoBio \\
\hline SARS-CoV-2 & VLP & Faz 1 & NCT04818281 & TUBİTAK \\
\hline \multirow[t]{2}{*}{ SARS-CoV-2 } & Lipid nanoparticle & Faz 3-Faz 2 & NCT04470427 & Moderna TX, Inc./ \\
\hline & (LNP)-encapsulated mRNA & & NCT04405076 & $\begin{array}{l}\text { National Institute of Allergy } \\
\text { and Infectious Diseases. }\end{array}$ \\
\hline SARS-CoV-2 & VLP & Faz 1/2 & ACTRN12620000817943 & Serum Institute of India \\
\hline SARS-CoV-2 & Lipid nanoparticle (LNP)-mRNA & Faz1/2 & NCT04480957 & Arcturus Therapeutics, Inc. \\
\hline SARS-CoV-2 & Lipid nanoparticle (LNP)-RNA & Faz 1 & ISRCTN17072692 & Imperial College London \\
\hline SARS-CoV-2 & Plant-derived coronavirus-like particle (VLP) & Faz 1 & NCT04450004 & Medicago \\
\hline
\end{tabular}

\section{SARS-CoV-2 (Covid-19) Salgınına Karşı} Geliştirilen Nanopartikül Așı Teknolojileri : SARS-CoV2 gibi dünya çapında büyük bir tehdit oluşturan salgınların varlığında nanoteknoloji ve nanotıbbın önemi giderek artmaktadır (Li vd., 2021). Pfizer/BioNTech ve Moderna mRNA aşıları için dağıtım aracı olarak lipid nanoparçacıkları kullanılmıştır, parçacık boyutlarının 80 ile $100 \mathrm{~nm}$ arasında olduğu rapor edilmiştir (Pilkington vd., 2021). Pfizer/BioNTech ve Moderna mRNA aşılarındaki lipid nanopartiküllerinin bileşimleri iyonize edilebilir katyonik lipid, PEGillenmiş lipid, kolesterol ve yardımcı lipid olarak fosfolipid distearoilfosfatidilkolin (DSPC)'den oluşmaktadır (Li vd., 2021) Pozitif yüklü lipid NP'ler tarafından örtülen mRNA, daha kararlıdır ve RNaz bozulmasına karşı dirençlidir (Li vd., 2021). Cohen vd. (2021) tarafindan SpyTag/SpyCatcher teknolojisi kullanılarak mozaik NP'ler, SARS-CoV-2'nin reseptör bağlama alanını (RBD-Receptor Binding Domain) oluşturacak şekilde tasarlanmıştır. $\mathrm{Bu}$ sistem, yüksek titrelerde nötralize edici antikorlar ortaya çıkaran 
multimerik SARS-CoV-2 RBD nanopartiküllerini hazırlamak için kullanılmıştır (Cohen vd., 2021) . Powell vd. (2021) SARS-CoV-2 S proteinini veya alt birimlerini görüntülemek için kendi kendine birleşen ferritin nanopartiküllerini kullanılarak bir nanopartiküler aşı üretmiştir. $\mathrm{Bu}$ aşı tipi, hayvan modellerinde güçlü nötralize edici antikorlar ve hücresel bağışıklık tepkileri sağlamıştır, SARSCoV-2 ve diğer koronavirüslere karşı umut verici bir aşılama yaklaşımı olarak kabul edilmektedir (Powell vd., 2021).

\section{TEŞEKKÜR}

$\mathrm{Bu}$ derleme YÖK 100/2000 aş1 çalı̧̧maları öncelikli alanı kapsamında bursiyer Evrim Dönmez tarafından gerçekleştirilen doktora 1. Seminerinden üretilmiştir.

\section{SONUÇ}

Geleneksel olarak inaktif veya attenue, virüs vektörlü ve subunit aşıların yanı sıra nanopartikül aşılar, aşı geliştirmenin zorluklarına karşı yenilikçi yaklaşımlar sunmaktadır. Konvansiyonel aşılar kayda değer bir başarı sağlasa da, güçlü antiviral tepkiler üretme yetenekleri sınırlıdır ve ani salgınlara karşı etkili immun yanıtlar elde etmede büyük zorluklar devam etmektedir. Geleneksel aş1 hazırlama yöntemleri, antijen çeşitliliği ve mutasyon oranları yüksek virüslere karşı aşı üretememekte, dolayısıyla aşıların geliştirilmesini sınırlandırmaktadır. Geleneksel aşılarla bu engelleri aşmak için birçok araştırmacı, iyi etkinlik, özgüllük ve uzun süreli antiviral tepkiye sahip nanopartikül aşıları tasarlamak ve üretmek için nanoteknolojiye yönelmiştir. Nanoteknolojinin immunomühendislik alanına uygulanmasıyla, yeni aşı taşıyıcıları sentezlenmekte ve hızla gelişmektedir. SARSCoV-2 virüsünün neden olduğu mevcut COVID-19 pandemisi gibi salgınların engellenmesinde, aşı geliştirme ve onayının hızlandırılması için acil bir ihtiyaç ortaya çıkmaktadır. Ayrıca yeni nano formülasyonlar, nanopartiküllerin adjuvan özelliklerini geliştirmek için immun sistemi uyarıcı molekülleri de içermektedir. NP'ler, invazif olmayan uygulama ve aşı antijenlerinin belirli bir yerde uzun süreli salınımı için uygun hale getirilebilmekte, böylece tek doz aşı uygulamasına olanak sağlamaktadır.

Gelecekte, nanopartiküler aşılar sadece immun yanıt uyarımı için değil, aynı zamanda NP'lerin antienfektif terapötik aktivitesinide ele alacağı düşünülmektedir. Hastalıkların tedavisi için NP'lerin uygulanmasında güvenlik tam olarak sağlandığı zaman nanopartikül aşıların kontrol edilebilir fiziksel ve yapısal özellikleri sayesinde oldukça ilgi çekici bir strateji olacağı savunulmaktadır.

\section{KAYNAKLAR}

Alexyuk, P.G., Bogoyavlenskiy, A.P., Alexyuk, M.S., Turmagambetova, A.S., Zaitseva, I.A., Omirtaeva, E.S. \& Berezin, V.E. (2019). Adjuvant activity of multimolecular complexes based on Glycyrrhiza glabra saponins, lipids, and influenza virus glycoproteins. Archives of Virology, 164(7), 1793-1803. DOI: 10.1007/s00705-019-04273-2

Altenburg, Arwen F., Kreijtz, J.H.C.M., de Vries, R.D., Song, F., Fux, R., Rimmelzwaan, G.F., Sutter, G. \& Volz, A. (2014). Modified vaccinia virus ankara (MVA) as production platform for vaccines against influenza and other viral respiratory diseases. Viruses, 6(7), 2735-2761. DOI: $10.3390 / \mathrm{v} 6072735$

Bahadoran, A., Moeini, H., Bejo, M.H., Hussein, M.Z. \& Omar, A.R. (2016). Development of tatconjugated dendrimer for transdermal DNA vaccine delivery. Journal of Pharmacy \& Pharmaceutical Sciences: A Publication of the Canadian Society for Pharmaceutical Sciences, Societe Canadienne Des Sciences Pharmaceutiques, 19(3), 325-338. DOI: 10.18433/J3G31Q

Borges, O., Cordeiro-da-Silva, A., Tavares, J., Santarém, N., de Sousa, A., Borchard, G. \& Junginger, H.E. (2008). Immune response by nasal delivery of hepatitis B surface antigen and codelivery of a $\mathrm{CpG}$ ODN in alginate coated chitosan nanoparticles. European Journal of Pharmaceutics and Biopharmaceutics: Official Journal of Arbeitsgemeinschaft Für Pharmazeutische Verfahrenstechnik e.V, 69(2), 405-416. DOI: 10.1016/j.ejpb.2008.01.019

Chahal, J.S., Khan, O.F., Cooper, C.L., McPartlan, J. S., Tsosie, J.K., Tilley, L.D., Sidik, S.M., Lourido, S., Langer, R., Bavari, S., Ploegh, H. L. \& Anderson, D.G. (2016). Dendrimer-RNA nanoparticles generate protective immunity against lethal Ebola, H1N1 influenza, and Toxoplasma gondii challenges with a single dose. Proceedings of the National Academy of Sciences of the United States of America, 113(29), E413342. DOI: $10.1073 /$ pnas. 1600299113

Chu, D., Gao, J. \& Wang, Z. (2015). Neutrophil-mediated delivery of therapeutic nanoparticles across blood vessel barrier for treatment of inflammation and infection. ACS Nano, 9(12), 11800-11811. DOI: 10.1021/acsnano.5b05583

Cohen, A.A., Gnanapragasam, P.N.P., Lee, Y.E., Hoffman, P.R., Ou, S., Kakutani, L.M., ... \& Bjorkman, P.J. (2021). Mosaic nanoparticles elicit cross-reactive immune responses to zoonotic coronaviruses in mice. Science (New York, N.Y.), 371(6530), 735-741. DOI: 10.1126/science.abf6840

Das, I., Padhi, A., Mukherjee, S., Dash, D.P., Kar, S. \& Sonawane, A. (2017). Biocompatible chitosan nanoparticles as an efficient delivery vehicle for 
Mycobacterium tuberculosis lipids to induce potent cytokines and antibody response through activation of $\gamma \delta$ T cells in mice. Nanotechnology, 28(16), 165101. DOI: 10.1088/1361-6528/aa60fd

Demento, S.L., Cui, W., Criscione, J.M., Stern, E., Tulipan, J., Kaech, S.M. \& Fahmy, T.M. (2012). Role of sustained antigen release from nanoparticle vaccines in shaping the $\mathrm{T}$ cell memory phenotype. Biomaterials, 33(19), 49574964. DOI: 10.1016/j.biomaterials.2012.03.041

Dobrovolskaia, M.A., Aggarwal, P., Hall, J.B. \& McNeil, S.E. (2008). Preclinical studies to understand nanoparticle interaction with the immune system and its potential effects on nanoparticle biodistribution. Molecular Pharmaceutics, 5(4), 487-495. DOI: 10.1021/mp800032f

Feng, Ganzhu, Jiang, Q., Xia, M., Lu, Y., Qiu, W., Zhao, D., Lu, L., Peng, G. \& Wang, Y. (2013). Enhanced immune response and protective effects of nano-chitosan-based DNA vaccine encoding T cell epitopes of Esat-6 and FL against Mycobacterium tuberculosis infection. PloS One, 8(4), 61135. DOI: 10.1371/journal.pone.0061135

Foged, C., Brodin, B., Frokjaer, S. \& Sundblad, A. (2005). Particle size and surface charge affect particle uptake by human dendritic cells in an in vitro model. International Journal of Pharmaceutics, 298(2), 315-322. DOI: 10.1016/j.ijpharm.2005.03.035

Gao, Y., Wijewardhana, C. \& Mann, J.F.S. (2018). Virus-like particle, liposome, and polymeric particle-based vaccines against HIV-1. Frontiers in Immunology, 9, $345 . \quad$ DOI: 10.3389/fimmu.2018.00345

Gregory, A.E., Williamson, E.D., Prior, J.L., Butcher, W.A., Thompson, I.J., Shaw, A.M. \& Titball, R.W. (2012). Conjugation of $Y$. pestis $\mathrm{F} 1$-antigen to gold nanoparticles improves immunogenicity. Vaccine, 30(48), 6777-6782. DOI: 10.1016/j.vaccine.2012.09.021

Keller, S., Wilson, J.T., Patilea, G.I., Kern, H.B., Convertine, A.J. \& Stayton, P.S. (2014). Neutral polymer micelle carriers with $\mathrm{pH}$-responsive, endosome-releasing activity modulate antigen trafficking to enhance CD8(+) T cell responses. Journal of Controlled Release: Official Journal of the Controlled Release Society, 191, 24-33. DOI: 10.1016/j.jconrel.2014.03.041

Kelly, H.G., Kent, S.J. \& Wheatley, A.K. (2019). Immunological basis for enhanced immunity of nanoparticle vaccines. Expert Review of Vaccines, 18(3), $269280 . \quad$ DOI: 10.1080/14760584.2019.1578216

Kheirollahpour, M., Mehrabi, M., Dounighi, N.M., Mohammadi, M. \& Masoudi, A. (2020). Nanoparticles and vaccine development. Pharmaceutical Nanotechnology, 8(1), 6-21. DOI: $10.2174 / 2211738507666191024162042$

Kim, S.T., Saha, K., Kim, C. \& Rotello, V.M. (2013). The role of surface functionality in determining nanoparticle cytotoxicity. Accounts of Chemical Research, 46(3), 681-691. DOI: 10.1021/ar3000647

Kolaczkowska, E. \& Kubes, P. (2013). Neutrophil recruitment and function in health and inflammation. Nature Reviews. Immunology, 13(3), 159-175. DOI: 10.1038/nri3399

Li, Y., Tenchov, R., Smoot, J., Liu, C., Watkins, S. \& Zhou, Q. (2021). A comprehensive review of the global efforts on COVID-19 vaccine development. ACS Central Science, 7(4), 512533. DOI: 10.1021/acscentsci.1c00120

Manish, M., Rahi, A., Kaur, M., Bhatnagar, R. \& Singh, S. (2013). A single-dose PLGA encapsulated protective antigen domain 4 nanoformulation protects mice against Bacillus anthracis spore challenge. PloS One, 8(4), e61885. DOI: 10.1371/journal.pone.0061885

Manolova, V., Flace, A., Bauer, M., Schwarz, K., Saudan, P. \& Bachmann, M.F. (2008). Nanoparticles target distinct dendritic cell populations according to their size. European Journal of Immunology, 38(5), 1404-1413. DOI: 10.1002/eji.200737984

Moon, J. J., Suh, H., Bershteyn, A., Stephan, M.T., Liu, H., Huang, B., Sohail, M., Luo, S., Um, S.H., Khant, H., Goodwin, J.T., Ramos, J., Chiu, W. \& Irvine, D.J. (2011). Interbilayer-crosslinked multilamellar vesicles as synthetic vaccines for potent humoral and cellular immune responses. Nature Materials, 10(3), 243-251. DOI: 10.1038/nmat2960

Niikura, K., Matsunaga, T., Suzuki, T., Kobayashi, S., Yamaguchi, H., Orba, Y., Kawaguchi, A., Hasegawa, H., Kajino, K., Ninomiya, T., Ijiro, K. \& Sawa, H. (2013). Gold nanoparticles as a vaccine platform: influence of size and shape on immunological responses in vitro and in vivo. ACS Nano, 7(5), 3926-3938. DOI: $10.1021 / \mathrm{nn} 3057005$

O'Hagan, D.T. (2007). MF59 is a safe and potent vaccine adjuvant that enhances protection against influenza virus infection. Expert Review of Vaccines, 6(5), 699-710. DOI: 10.1586/14760584.6.5.699

Perisé-Barrios, A.J., Jiménez, Pereira de Oliveira, M., Garcion, E., Venisse, N., Benoit, J.-P., Couet, W. \& Olivier, J.-C. (2005). Tissue distribution of indinavir administered as solid lipid nanocapsule formulation in mdr1a (+/+) and mdr1a (-/-) CF-1 mice. Pharmaceutical Research, 22(11), 18981905. DOI: $10.1007 / \mathrm{s} 11095-005-7147-6$

Pilkington, E.H., Suys, E.J.A., Trevaskis, N.L., Wheatley, A.K., Zukancic, D., Algarni, A., AlWassiti, H., Davis, T.P., Pouton, C.W., Kent, S. J. \& Truong, N.P. (2021). From influenza to COVID-19: Lipid nanoparticle mRNA vaccines at the frontiers of infectious diseases. Acta Biomaterialia, 131, 16-40.

Powell, A.E., Zhang, K., Sanyal, M., Tang, S., Weidenbacher, P.A., Li,S., Kim, P.S. (2021). A 
single immunization with spike-functionalized ferritin vaccines elicits neutralizing antibody responses against SARS-CoV-2 in mice. ACS Central Science, 7(1), 183-199. DOI: 10.1021/acscentsci.0c01405

Prego, C., Paolicelli, P., Díaz, B., Vicente, S., Sánchez, A., González-Fernández, A. \& Alonso, M.J. (2010). Chitosan-based nanoparticles for improving immunization against hepatitis B infection. Vaccine, 28(14), 2607-2614. DOI: 10.1016/j.vaccine.2010.01.011

Reddy, S.T., van der Vlies, A.J., Simeoni, E., Angeli, V., Randolph, G.J., O'Neil, C.P., Lee, L.K., Swartz, M.A. \& Hubbell, J.A. (2007). Exploiting lymphatic transport and complement activation in nanoparticle vaccines. Nature Biotechnology, 25(10), 1159-1164. DOI: $10.1038 /$ nbt 1332

Ribeiro, A.M., Souza, A.C.O., Amaral, A.C., Vasconcelos, N.M., Jeronimo, M.S., Carneiro, F.P., Faccioli, L.H., Felipe, M.S.S., Silva, C.L. \& Bocca, A.L. (2013). Nanobiotechnological approaches to delivery of DNA vaccine against fungal infection. Journal of Biomedical Nanotechnology, $\quad \mathbf{9}(2), \quad 221-230 . \quad$ DOI: 10.1166/jbn.2013.1491

Shae, D., Postma, A. \& Wilson, J.T. (2016). Vaccine delivery: where polymer chemistry meets immunology. Therapeutic Delivery, 7(4), 193 196. DOI: $10.4155 /$ tde-2016-0008

Shah, P., Bhalodia, D. \& Shelat, P. (2010). Nanoemulsion: A pharmaceutical review. Systematic Reviews in Pharmacy, 1(1), 24. DOI: 10.4103/0975-8453.59509

Tao, W. \& Gill, H.S. (2015). M2e-immobilized gold nanoparticles as influenza A vaccine: Role of soluble M2e and longevity of protection. Vaccine, 33(20), 2307-2315. DOI: 10.1016/j.vaccine.2015.03.063

Temchura, V.V., Kozlova, D., Sokolova, V., Uberla, K. \& Epple, M. (2014). Targeting and activation of antigen-specific B-cells by calcium phosphate nanoparticles loaded with protein antigen. Biomaterials, 35(23), 6098-6105. DOI: 10.1016/j.biomaterials.2014.04.010

Thomas, C., Rawat, A., Hope-Weeks, L. \& Ahsan, F. (2011). Aerosolized PLA and PLGA nanoparticles enhance humoral, mucosal and cytokine responses to hepatitis B vaccine. Molecular Pharmaceutics, 8(2), 405-415. DOI: 10.1021/mp100255c

U.S. National Library of Medicine. (2021). Clinical Trials, Rockville Pike Bethesta, $\mathrm{mD}$. https://clinicaltrials.gov/. (Temmuz 2021)

Xu, L., Liu, Y., Chen, Z., Li, W., Liu, Y., Wang, L., Liu, Y., Wu, X., Ji, Y., Zhao, Y., Ma, L., Shao, Y. \& Chen, C. (2012). Surface-engineered gold nanorods: promising DNA vaccine adjuvant for HIV-1 treatment. Nano Letters, 12(4), 2003-2012. DOI: $10.1021 / \mathrm{nl} 300027 \mathrm{p}$
Yu, M., Jambhrunkar, S., Thorn, P., Chen, J., Gu, W. \& Yu, C. (2013). Hyaluronic acid modified mesoporous silica nanoparticles for targeted drug delivery to CD44-overexpressing cancer cells. Nanoscale, $\quad 5(1), \quad$ 178-183. DOI: 10.1039/c2nr32145a

Zhao, K., Chen, G., Shi, X.-M., Gao, T.-T., Li, W., Zhao, Y., Zhang, F.-Q., Wu, J., Cui, X. \& Wang, Y.-F. (2012). Preparation and efficacy of a live newcastle disease virus vaccine encapsulated in chitosan nanoparticles. PloS One, 7(12), e53314. DOI: 10.1371/journal.pone.0053314

Zhu, M., Wang, R. \& Nie, G. (2014). Applications of nanomaterials as vaccine adjuvants. Human Vaccines \& Immunotherapeutics, 10(9), 27612774. DOI: $10.4161 / \mathrm{hv} .29589$ 